(2) Open Access Full Text Article

REVIEW

\title{
Immunotherapeutics for Ebola Virus Disease: Hope on the Horizon
}

This article was published in the following Dove Press journal:

Biologics: Targets and Therapy

\section{Kyle L O'Donnell \\ Andrea Marzi (D)}

Laboratory of Virology, Division of Intramural Research, National Institute of Allergy and Infectious Diseases, National Institutes of Health, Hamilton, MT, USA
Correspondence: Andrea Marzi Email marzia@niaid.nih.gov

\begin{abstract}
Ebola virus disease (EVD) remains among the biggest public health threats in Africa, even though recently a vaccine was approved for human use. However, in outbreak situations treatment strategies are needed in combination with vaccination campaigns to impact and stop the spread of the disease. Here, we discuss the development of the immunotherapeutics against EDV both targeting the virus itself and bolstering the immunological environment of the host at both the pre-clinical and clinical level. The early development of antibody therapy in preclinical settings and the early pitfalls in the implementation of this therapeutic strategy are discussed. We also consider the advancement of the production, modulation, and specificity of the antibody treatment that garnered increased success in preclinical studies to the point that it was warranted to test them in a clinical setting. Initial clinical trials in an outbreak scenario proved difficult to definitively confirm the efficacy of the implemented treatment. Upon further modification and with the experiences from the challenging outbreak conditions in mind, the PALM clinical trial demonstrated efficacy of an antibody cocktail which recently received approval for human use.
\end{abstract}

Keywords: Ebolaviruses, filovirus, immune response, monoclonal antibodies, interferon

\section{Introduction}

Ebola virus is a member of the Filoviridae family which encompasses six genera: Ebolavirus, Marburgvirus, Striavirus, Thamnovirus, Dianlovirus, and Cuevavirus. ${ }^{1}$ The genus Ebolavirus includes six species Zaire ebolavirus (EBOV), Sudan ebolavirus (SUDV), Taï Forest ebolavirus, Reston ebolavirus, Bundibugyo ebolavirus (BDBV), and Bombali ebolavirus. Filoviruses are pleomorphic in shape and possess a lipid envelope. The viral genome is a negative-sense single strand RNA which is approximately $19 \mathrm{~kb}$ in size. ${ }^{1}$

Since the first outbreak in 1976, EBOV has resurfaced a multitude of times in Africa. Initially, it was responsible for causing small, localized outbreaks until 2013, when the large multinational epidemic was recorded causing 28,646 infections and 11,323 fatalities. ${ }^{2}$ A second, large outbreak occurred in the North Kivu province of the Democratic Republic of Congo (DRC) in 2018-2020 totaling 3481 cases and 2299 fatalities., 3 There has recently been an outbreak in the Equateur province, which was declared over on November 18 th, $2020 .^{5}$

Ebola virus disease (EVD) typically progresses in three stages. The first stage presents with non-specific flu-like symptoms. In the second stage, the disease progresses to include gastrointestinal symptoms and severe dehydration. During the third and final stage, the patient rapidly declines presenting with convulsion, mucosal 
bleeding, shock, and multi-organ failure leading to death. Convalescence can be a prolonged period of weeks to months with the potential of viral persistence in immune privileged sites. ${ }^{6,7}$ Post-exposure treatment options rely extensively on supportive care measures, such as fluid and electrolyte replacement, which is difficult to achieve in many African countries with poor healthcare infrastructure. ${ }^{8}$ A major focus of immunotherapeutic development for EVD is the production of antibody-based treatments. ${ }^{9}$ The continual improvement on the production and genetic manipulation of monoclonal antibodies has made this an attractive production pipeline. Monoclonal antibodies can now be produced efficiently in large quantities, but also can be modified to improve the antiviral capabilities allowing for the production of broadly protective antibodies. ${ }^{9}$ Despite targeting the virus, attempts have also been made to bolster the host antiviral responses with immune-stimulatory compounds like interferons (IFNs) (Figure 1). This review will focus on the status of EVD immunotherapeutics, both in pre-clinical and clinical stages, with an emphasis on monoclonal antibody intervention.

\section{Antibody Therapy}

Antibody therapy may be one of the oldest forms of disease therapy, with the passive delivery of antibodies at very high concentrations in colostrum and breast milk. ${ }^{10}$ Antibodies present in these biological fluids evolved and are specifically tailored to the pathogenic environment exposed to newborns. This demonstrates the appealing characteristics of antibodies as a drug platform. Due to their high specificity, there is a decreased likelihood of off-target binding, bolstering the safety profile of new products being developed. ${ }^{11,12}$ The utilization of antibody therapy for EVD was initially subject to debate. An initial report from the EBOV outbreak in Kikwit, DRC in 1995 found that eight patients who were treated with convalescent whole blood transfusions had a survival rate of $87.5 \%$, however, due to the limited number of patients and the nature of the study, the authors were concerned about what conclusions could be drawn. ${ }^{13}$

\section{Preclinical Efficacy of Antibody Therapy}

One of the earliest reports of passive immunization of nonhuman primates (NHP) to combat EVD was led by Russian scientists who treated baboons with an equine hyperimmune $\operatorname{IgG}$ preparation. A single dose of the equine IgG with high neutralizing titers provided $100 \%$ efficacy when given prior to or up to one-hour post challenge. When the time between challenge and treatment was extended to two hours, the efficacy dramatically dropped to under $30 \% .{ }^{14}$ A similar study was conducted and no

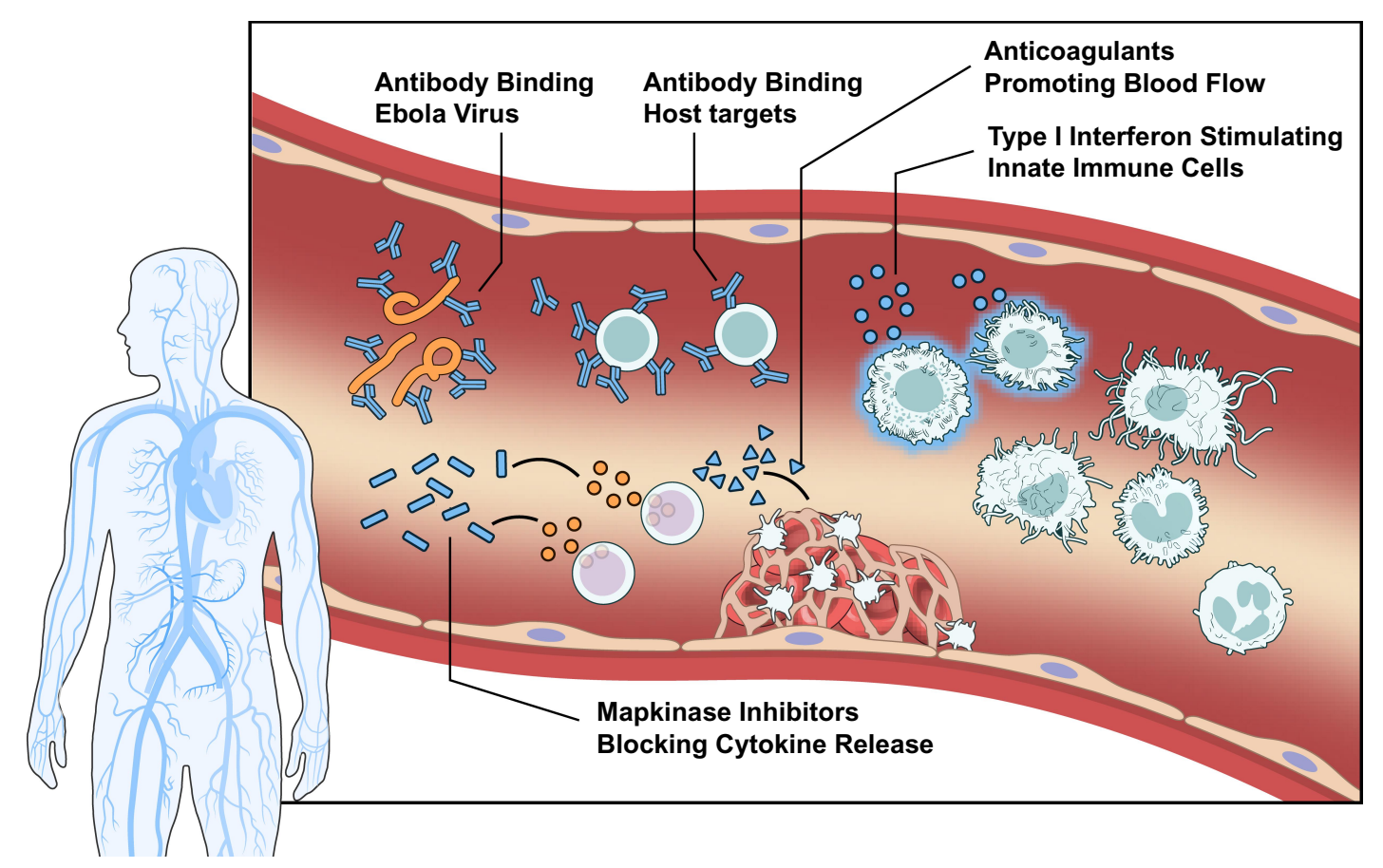

Figure I Schematic of the cellular and physiological targets of immunotherapeutics against EVD. Immunotherapeutics can target the virus directly such as neutralizing antibodies, or they can target cellular processes or receptors. Immunotherapeutics can also be cell stimulators such as interferon treatment to bolster the antiviral response. 
therapeutic effects were observed when equine IgG was administered to NHPs immediately after infection. ${ }^{15}$ In a more recent study, EBOV-specific polyclonal equine Fab fragments uniformly protected NHPs when 7 doses were administered starting either 3 or 5 days post-infection (dpi). This study demonstrated that a higher dose (100 mg/ $\mathrm{kg}$ ) and multiple treatments significantly improve antibody therapy efficacy. ${ }^{16}$

The process of monoclonal antibody implementation took great strides in the mid to late 1900 s, with the realization that species matching is crucial to maintain efficacy. This new understanding prompted the generation of humanized antibodies. With the early success of convalescent blood transfusions, researchers utilized EVD survivors to isolate potent neutralizing antibodies. One such neutralizing antibody is KZ52. ${ }^{17}$ This monoclonal antibody showed strong protective efficacy in guinea pigs against EVD up until 6 hours post infection. ${ }^{18}$ However, when KZ52 was advanced to NHPs, no evidence of protection from EVD was observed in 3 of the 4 treated animals. The fourth animal was euthanized 28 dpi when it became moribund and despite having no circulating EBOV, high viral depositions in various organs were found. ${ }^{19}$ This was the first indication that neutralization of free virus in blood was not sufficient to protect from EVD.

The first real success with antibody post-exposure treatment was reported in 2012 when Dye et al purified IgG from convalescent serum of macaques which survived EBOV challenge following experimental vaccination. ${ }^{20}$ Treatment of naïve NHPs with purified polyclonal IgG 48 hours post EBOV challenge resulted in $100 \%$ protection. Interestingly, the effective concentrations at $50 \%$ $\left(\mathrm{EC}_{50}\right)$ and $80 \%\left(\mathrm{EC}_{80}\right)$ of the purified $\mathrm{IgG}$ preparation were lower than that of KZ52, which offered no protection. The authors speculated that the efficacy was likely improved due to the increase in epitope recognition by this polyclonal IgG preparation compared to a single monoclonal antibody (mAb). This was the first indication that a cocktail of mAbs could potentially provide complete protection against EVD.

Shortly thereafter, $3 \mathrm{mAb}$ cocktails demonstrated complete or partial protection when administered to EBOVinfected NHPs post-exposure. ${ }^{21-23}$ One such cocktail was a combination of three murine antibodies initially termed ZMab. ZMab demonstrated 100\% efficacy in NHPs when administered 1dpi, and 50\% efficacy when administered 2 dpi. $^{22}$ Another cocktail was a combination of 3 plant- produced human-mouse chimeric mAbs termed MB-003 The authors reported that MB-003 showed a 67\% efficacy when administered 1 or $2 \mathrm{dpi}^{23}$ Particularly noteworthy is that the plant-based production of the MB-003 yielded afucosylated mAbs. This is a critical step forward, as it has been shown that afucosylated mAbs are able to induce antibody-dependent cellular cytotoxicity (ADCC) at a much more efficient rate. $^{23-26}$ Following the postexposure treatment success, the authors went on to extend the time to treatment based on clinical signs mimicking the time when patients would present themselves at hospitals. The animals received treatment after onset of fever and viremia at $4 \mathrm{dpi}$; however, only $42 \%$ of the animals survived. $^{27}$ The developers of ZMab and MB-003 then combined efforts to chimerize the ZMab mAbs and identified the most potent combination of three mAbs. ${ }^{28}$ The new combination, now termed ZMapp $^{\mathrm{TM}}$, demonstrated $100 \%$ efficacy when administered as late as $5 \mathrm{dpi}$ to EBOV-infected NHPs. These results were similar to a single human mAb, mAb114. This antibody binds to an epitope on the GP spanning the glycan cap on GP1. ${ }^{29}$ When administered therapeutically, mAB114 also demonstrated $100 \%$ efficacy $5 \mathrm{dpi}$ in EBOV-infected NHPs. ${ }^{30}$ The success of this single mAb was attributed to not only the structural epitope it recognized and its robust neutralization capabilities, but also to its ability to induce ADCC which was demonstrated in vitro. ${ }^{30} \mathrm{~A}$ third $\mathrm{mAb}$ cocktail, REGN-EB3, is a combination of 3 human mAbs, which in preclinical studies protected $80-100 \%$ of NHPs when administered 5 dpi. The survival of the animals depended on the dose frequency and concentration. A dose of $100 \mathrm{mg} / \mathrm{mL}$ is the minimum dose required for maximum improvement of symptoms. ${ }^{31}$ REGN-EB3 has a number of different mechanism of action including ADCC, phagocyte stimulation, virus internalization inhibition, and neutralization. ${ }^{32}$

While the window of post-exposure therapy was extended to 5 dpi with ZMapp and mAb114, the breadth of coverage within the filovirus family remained a concern, prompting the need for a broadly protective $\mathrm{mAb}$ or mAb cocktail. Recently, this has been accomplished with a mAb cocktail that provides protection against challenge with multiple members of the Ebolavirus genus. ${ }^{33} \mathrm{MBP} 134^{\mathrm{AF}}$ is a mAb cocktail containing 2 broadly neutralizing afucosylated mAbs. A single dose administered 4 dpi resulted in $100 \%$ efficacy when NHPs were challenged with EBOV. A similar result was obtained when NHPs were challenged with SUDV and 
treated with a single dose $5 \mathrm{dpi}$. MBP $134^{\mathrm{AF}}$ was then tested against NHPs challenged with a lethal dose of BDBV and treated at $7 \mathrm{dpi}$. Despite one of the 6 challenged animals succumbing to the infection, MBP134 ${ }^{\mathrm{AF}}$ demonstrated a high rate of therapeutic efficacy 7 dpi. $^{33,34}$ This was the first broadly neutralizing mAb cocktail to break the paradigm of "one bug, one drug", which is vital in an outbreak scenario for ebolaviruses where the exact identity of the virus may be unknown due to the overlap in endemic areas. MBP $134^{\mathrm{AF}}$ as of now is not yet evaluated in clinical trials and is still in the pre-clinical stage of development. To build upon these findings, bispecific antibodies are being developed to further consolidate the treatment to a single antibody with multiple targets. An example of this is described in Wec et al, where a "Trojan horse" bispecific antibody was developed which recognized the receptor binding site of the GP, and Niemann-Pick $\mathrm{C} 1$ receptor within the late endosome to broadly inhibit multiple ebolaviruses. ${ }^{35}$

\section{Clinical Evaluation of mAb Cocktails}

With the promising data from pre-clinical studies, ZMapp was accelerated for use in clinical trials during the 2013-2016 EBOV epidemic in West Africa. A randomized, controlled clinical trial was conducted with a 1:1 ratio of participants receiving standard of care to participants receiving standard of care with the administration of $50 \mathrm{mg} / \mathrm{kg}$ ZMapp every third day. ${ }^{36}$ Patients were stratified according to viremia as assessed by PCR cycle threshold values and the primary endpoint of the study was mortality at 28 days. A total of 71 patients were evaluated with a case fatality rate (CFR) of $30 \%$. When comparing the groups, the CFR of the standard of care alone was $37 \%$ while the CFR with the addition of ZMapp was $22 \%$. While there was a beneficial trend observed attributed to the inclusion of ZMapp, the difference between the groups fell short of the predetermined threshold in the study parameters to conclude a significant improvement in patient outcome. A confounding factor in the study is that the antiviral compound Favipiravir was included in the standard of care possibly overshadowing the outcome of treatment with ZMApp alone. ${ }^{36}$

More recently, the Pamoja Tulinde Maisha (PALM) study was conducted as a randomized, controlled Phase 2/3 trial for 4 reagents-ZMapp, Remdesivir (small molecule antiviral), mAb114 and REGN-EB3-during the
2018-2020 EBOV outbreak in DRC. The group receiving standard of care and ZMapp was defined as the control group. The CFR for patients in this group was $50 \%$, which is similar to the group that received standard of care and Remdesivir (53\%). The 28-day CFR was significantly reduced to $34 \%$ with the addition of mAb114, ${ }^{30,37}$ which was demonstrated to be well tolerated and easy to administer, via intravenous infusion for 30 minutes, in a previous Phase 1 trial. $^{37}$ Similarly, the 28-day CFR was at $35 \%$ when patients received standard of care plus REGN-EB3 (a mixture of 3 mAbs) also administered intravenously. ${ }^{31,38}$ The PALM study represents a remarkable step forward in the implementation of therapeutic mAb intervention to significantly reduce the CFR. There are currently 2 clinical trials in progress to assess the efficacy and benefits of mAb therapy. The first is an expanded access protocol, based on the results of the PALM study, to allow for wider emergency use of REGNEB3. Two mothers were admitted to the treatment center and confirmed to be PCR positive and were included in the treatment groups. Upon birthing of their children both infants were PCR negative and remained negative for 21 days after birth. ${ }^{39}$ This small sample size led to the expansion of the trial which allows the inclusion of children of any age and pregnant women (NCT03576690). The inclusion of these at high-risk populations is critical to determining the breath of therapeutic intervention for high-risk individuals who fall into these categories. The second ongoing study is the continuation of the PALM study. In August 2019, the safety monitoring board reviewed the interim data from the study and determined that mAb114 and REGN-EB3 were superior to ZMapp and required all future patients to be allocated to either the mAb114 or REGN-EB3 groups ${ }^{40}$ (NCT03719586). With the results obtained from these 2 trials, in October 2020 the US Food and Drug Administration (FDA) approved REGNEB3 as the first treatment for EBOV. ${ }^{31}$ A significant step forward is the approval of this treatment for newborns of mothers that tested positive for the infection. ${ }^{41}$

\section{Type I Interferon Intervention}

The type I IFNs, IFN- $\alpha$ and IFN- $\beta$, have previously been utilized clinically for their broad spectrum antiviral activity. ${ }^{42}$ EBOV infection effectively inhibits early IFN production and signaling through functions from its viral proteins VP24 and VP35. ${ }^{43}$ Early NHP studies indicated that IFNs were able to prolong time to death in both the rhesus as well and the cynomolgus macaque model. ${ }^{44,45}$ 
While none of these treated animals survived the infection, the studies reported a delayed time to death suggesting a limited effectiveness of the treatment. While IFNs are no longer considered a stand-alone treatment for EVD, these results labeled them as an attractive compound for combination therapy. When vector-expressed IFN- $\alpha$ was combined with ZMab, the therapeutic efficacy and treatment window increased from $50 \%$ survival at 2 dpi to $100 \%$ survival at $3 \mathrm{dpi}$ in the rhesus macaque model. ${ }^{45}$ Upon further in vitro analysis, it was determined that IFN- $\beta$ 1a is superior to IFN- $\alpha$ in antiviral potency. ${ }^{46}$ During the 2013-2016 epidemic, a small clinical trial in Guinea enrolled 9 patients for IFN- $\beta$ 1a treatment. The survival for treated patients was $67 \%$ in contrast to the control cohort $(19 \%)$, which is a significant increase. However, viral clearance was not significantly changed in the survivors in either cohort and we are not aware of other clinical trials conducted with IFN- $\beta$ 1a. ${ }^{47}$

\section{Alternative Immunotherapeutics}

While the predominate immunotherapeutic for EVD is the administration of $\mathrm{mAb}$ targeting the virion directly, alternative strategies are also pursued. One is the use of antibodies targeting cellular proteins involved in the entry step of EBOV. T cell immunoglobulin and mucin-1 (TIM-1) has been shown to bind to the EBOV glycoprotein (GP) and facilitate attachment and entry into host cells. The human anti-TIM-1 mAb ARD5 demonstrated the ability to inhibit GP-mediated pseudovirion and wild-type EBOV infection in vitro, ${ }^{48}$ however, we are not aware of a study demonstrating preclinical efficacy of ARD5 against EVD.

The modulation of early innate immunological pathways has also been investigated to combat EVD. Filovirus GPs are heavily glycosylated and contain high-mannose chains which allow for mannose-binding lectin (MBL) to bind to EBOV and facilitate complement-dependent virus neutralization. ${ }^{49,50}$ EBOV-infected mice treated twice daily with high doses of MBL resulted in $40 \%$ survival when administered pre- or post-exposure. ${ }^{50}$ No further preclinical data are available.

Modulation of the immunological response resulting from the virus infection has also been investigated. Utilizing mitogen-activated protein kinase (MAPK) inhibitors it was shown that EBOV replication can be blocked in differentiated human antigen presenting cells. This block also diminished the cytokine response elicited by these cells. ${ }^{51}$ Another approach that has been attempted and even implemented in the clinical setting was the treatment of the coagulation abnormalities and hemorrhagic manifestations during EVD. Recombinant human activated protein $\mathrm{C}$ (rhAPC) and recombinant nematode anticoagulant protein $\mathrm{c} 2$ (rNAPc2) have been investigated. When tested in a NHP model the rhAPC resulted in an increased time to death, but only $18 \%$ survival rate. ${ }^{52}$ The rNAPc 2 was tested in NHPs 10 minutes and 24 hours postexposure and each group resulted in prolonged survival time and a $33 \%$ survival rate. ${ }^{53}$ These approaches have not been tested in clinical trials alone but were used in combination therapy approaches during the epidemic.

In the 2013-2016 epidemic, a medical doctor was on supportive care when he was treated with an experimental fibrin-derived peptide which was being developed for vascular leakage syndrome; the patient fully recovered. ${ }^{54}$ Many of these alternative approaches have not gained the traction to progress into clinical trials but are a necessity to the basic understanding of how different approaches to intervention can affect the disease outcome.

\section{Room for Improvement}

While the PALM study was a great success and brought about the first FDA-approved therapeutic for EVD, the study was not without its drawbacks. Patients presenting at admission with a CT value of 22 or less have the highest risk of death and had an unacceptable high CFR. These high-risk patients treated with supportive care and mAb114 or REGNEB3 had a CFR of $70 \%$ or $64 \%$, respectively. These CFRs are improvements compared to ZMapp 84\% and Remdesivir $85 \%$, still 2 out of 3 patients succumbed to the disease. Improvement in supportive care, and combinational therapeutic intervention with complementary mechanisms of action are being investigated to combat this issue. The application of therapeutic benefits and the therapeutic window determined in preclinical studies in NHP models is difficult to translate to human clinical cases of EVD. A majority of patients in the PALM study did not seek medical attention until on average 5.5 days after the onset of symptoms. In addition to the prolonged symptomatic period and a conservative estimate of the typical incubation period of 6-10 days, this suggests that clinical intervention was not administered until 11-12 days post-exposure. This is almost twice the typical timeframe for interventions to be are applied in preclinical NHP studies, which accentuates the remaining gap in preclinical model systems. A recent study on the implementation of supportive care in an intensive care unit on NHPs demonstrated that all supportive care measures did little to slow the disease progression with all NHPs reaching 
the terminal endpoint by around $7 \mathrm{dpi}{ }^{55}$ The time course of disease in NHP is compressed compared to that of human cases. However, this means that therapeutics to treat highrisk patients need to combat the ongoing viral replication as well as quell the systemic inflammatory response and organ failure.

Surviving acute EVD is the first step to a healthy outcome, but not the only step. Our understanding of EVD sequelae continues to develop as more attention is paid to survivors of the disease. During the acute phase of the disease, EBOV might infiltrate immune-privileged tissues such as the brain, eyes, and sexual organs leading to viral persistence. The development of persistent infection is both a health risk for the patient, by developing organspecific inflammatory syndrome, and the public, due to the risk of unintentional disease transmission. ${ }^{56-62}$ The question remains if anti-EBOV therapeutics will have an effect on viral persistence.

Finally, as touched on earlier, the therapeutic breadth of the treatments needs to be expanded. The therapeutics tested in the PALM study have a narrow therapeutic spectrum, being effective only against EBOV with minimal cross-reactivity to other human-pathogenic ebolaviruses with sometimes overlapping endemic areas. It has been mentioned that broadly neutralizing antibodies against ebolaviruses are in development that may fill this gap, but they have yet to be tested in a clinical setting. Combination therapy with mAbs and a broadspectrum antiviral such as Remdesivir or other antivirals could also fill this gap.

\section{Conclusion}

The advancement of immunotherapeutics for EVD started as what looked like an unsuccessful avenue of research and has developed to the pinnacle of clinical research with a FDAapproved treatment for EVD. There is still considerable work needed to be done to optimize the treatment regimens to improve the efficacy in patients most at risk of death and how to combat viral sequelae. In addition, there is the improvement of defining therapeutic roles and advancing supportive care in resource limited settings. These lingering questions emphasize that there is no time for complacency even in the wake of a therapeutic approval.

\section{Acknowledgments}

We thank Ryan Kissinger (NIAID, NIH) for assistance with figure generation. Filovirus research in the
Immunobiology \& Molecular Virology Unit is supported by the Intramural Research Program, NIAID, NIH.

\section{Disclosure}

The authors report no conflicts of interest.

\section{References}

1. Kuhn JH, Amarasinghe GK, Basler CF, et al. ICTV Virus taxonomy profile: filoviridae. J Gen Virol. 2019;100(6):911-912. doi:10.1099/ jgv.0.001252

2. Bell BP, Damon IK, Jernigan DB, et al. Overview, control strategies, and lessons learned in the CDC response to the 2014-2016 Ebola Epidemic. Morbidity Mortality Weekly Rep. 2016;1(65):4-11.

3. World Health Organization. Ebola virus disease Democratic Republic of Congo: external situation report 98/ 2020; 2020. Available from: https://www.who.int/publications/i/item/10665-332654.Accessed November 18, 2020.

4. World Health Organization. Regional Office for Africa. Ebola Virus Dis. 2019.

5. Center for Disease Control and Prevention. 2020 Democratic Republic of the Congo, Equateur province; 2020. CDC. Available from: https://www.cdc.gov/vhf/ebola/outbreaks/drc/2020-june.html. Accessed December 6, 2020.

6. Feldmann H, Geisbert TW. Ebola haemorrhagic fever. Lancet. 2011;377(9768):849-862. doi:10.1016/S0140-6736(10)60667-8

7. Kortepeter MG, Bausch DG, Bray M. Basic clinical and laboratory features of filoviral hemorrhagic fever. J Infect Dis. 2011;204(Suppl 3):S810-S816. doi:10.1093/infdis/jir299

8. Fowler RA, Fletcher T, Fischer WA 2nd, et al. Caring for critically ill patients with ebola virus disease. Perspectives from West Africa. Am J Respir Crit Care Med. 2014;190(7):733-737. doi:10.1164/rccm.20 1408-1514CP

9. Lu RM, Hwang YC, Liu IJ, et al. Development of therapeutic antibodies for the treatment of diseases. J Biomed Sci. 2020;27(1):1.

10. Wheeler TT, Hodgkinson AJ, Prosser CG, Davis SR. Immune components of colostrum and milk - a historical perspective. J Mammary Gland Biol Neoplasia. 2007;12(4):237-247. doi:10.1007/s10911-00 7-9051-7

11. Reichert JM, Rosensweig CJ, Faden LB, Dewitz MC. Monoclonal antibody successes in the clinic. Nat Biotechnol. 2005;23(23): 1073-1078. doi:10.1038/nbt0905-1073

12. Reichert JM. Trends in the development and approval of monoclonal antibodies for viral infections. BioDrugs. 2007;21(1):1-7. doi:10.21 65/00063030-200721010-00001

13. Mupapa K, Massamba M, Kibadi K, et al. Treatment of Ebola hemorrhagic fever with blood transfusions from convalescent patients. International Scientific and Technical Committee. $J$ Infect Dis. 1999;179(Suppl 1):S18-S23. doi:10.1086/514298

14. Kudoyarova-Zubavichene NMSN, Chepurnov AA, Netesov SV. Preparation and use of hyperimmune serum for prophylaxis and therapy of Ebola virus infections. J Infect Dis. 1999;179:218-223. doi: $10.1086 / 514294$

15. Jahrling PB. Passive Immunization of Ebola Virus-Infected Cynomolgus Monkeys with Immunoglobulin from Hyperimmune Horses. Vol. 11. Vienna: Springer; 1996.

16. Wang $\mathrm{H}$, Wong $\mathrm{G}$, Zhu W, et al. Equine-origin immunoglobulin fragments protect nonhuman primates from ebola virus disease. J Virol. 2019;93(5):e01548-e01518. doi:10.1128/JVI.01548-18

17. Maruyama T, Rodrifuez LL, Jahrling PB, et al. Ebola virus can be effectively neutralized by antibody produced in natural human infection. J Virol. 1999;73(7):6024-6030. doi:10.1128/JVI.73.7.602 4-6030.1999 
18. Parren PW, Geisbert TW, Maruyama T, Jahrling PB, Burton DR. Preand postexposure prophylaxis of Ebola virus infection in an animal model by passive transfer of a neutralizing human antibody. $J$ Virol. 2002;76(12):6408-6412. doi:10.1128/JVI.76.12.6408-6412.2002

19. Oswald WB, Geisbert TW, Davis KJ, et al. Neutralizing antibody fails to impact the course of Ebola virus infection in monkeys. PLoS Pathog. 2007;3(1):e9. doi:10.1371/journal.ppat.0030009

20. Dye JM, Herbert AS, Kuehne AI, et al. Postexposure antibody prophylaxis protects nonhuman primates from filovirus disease. Proc Natl Acad Sci U S A. 2012;109(13):5034-5039. doi:10.1073/ pnas. 1200409109

21. Marzi A, Yoshida R, Miyamoto H, et al. Protective efficacy of neutralizing monoclonal antibodies in a nonhuman primate model of Ebola hemorrhagic fever. PLoS One. 2012;7(4):e36192. doi:10. 1371/journal.pone.0036192

22. Qiu X, Audet J, Wong G, et al. Successful treatment of ebola virus-infected cynomolgus macaques with monoclonal antibodies. Sci Transl Med. 2012;4(138):138ra181. doi:10.1126/scitranslmed.3003876

23. Olinger GG Jr, Pettitt J, Kim D, et al. Delayed treatment of Ebola virus infection with plant-derived monoclonal antibodies provides protection in rhesus macaques. Proc Natl Acad Sci U S A. 2012;109 (44):18030-18035. doi:10.1073/pnas. 1213709109

24. Zeitlin L, Pettitt J, Scully C, et al. Enhanced potency of a fucose-free monoclonal antibody being developed as an Ebola virus immunoprotectant. Proc Natl Acad Sci U S A. 2011;108 (51):20690-20694. doi:10.1073/pnas.1108360108

25. Saunders KO. Conceptual approaches to modulating antibody effector functions and circulation half-life. Front Immunol. 2019;10:1296. doi:10.3389/fimmu.2019.01296

26. Liu Q, Fan C, Li Q, et al. Antibody-dependent-cellular-cytotoxicityinducing antibodies significantly affect the post-exposure treatment of Ebola virus infection. Sci Rep. 2017;7(1):45552. doi:10.1038/srep 45552

27. Pettitt J, Zeitlin L, Kim Do H, et al. Therapeutic Intervention of Ebola virus infection in rhesus macaques with the MB-003 Monoclonal Antibody Cocktail. Sci Transl Med. 2013;5(199): 199ra113. doi:10.1126/scitranslmed.3006608

28. Qiu X, Wong G, Audet J, et al. Reversion of advanced Ebola virus disease in nonhuman primates with ZMapp. Nature. 2014;514 (7520):47-53. doi:10.1038/nature 13777

29. Misasi J, Gilman MS, Kanekiyo M, et al. Structural and molecular basis for Ebola virus neutralization by protective human antibodies. Science. 2016;351(6279):1343-1346. doi:10.1126/science.aad6117

30. Corti D, Misasi J, Mulangu S, et al. Protective monotherapy against lethal Ebola virus infection by a potently neutralizing antibody. Science. 2016;351(6279):1339-1342. doi:10.1126/science.aad5224

31. Pascal KE, Dudgeon D, Trefry JC, et al. Development of clinical-stage human monoclonal antibodies that treat advanced ebola virus disease in nonhuman primates. J Infect Dis. 2018;218 (suppl_5):S612-S626. doi:10.1093/infdis/jiy285

32. Markham A. REGN-EB3: first approval. Drugs. 2021;81(1):175-178. doi:10.1007/s40265-020-01452-3

33. Wec AZ, Bornholdt ZA, He S, et al. Development of a human antibody cocktail that deploys multiple functions to confer pan-ebolavirus protection. Cell Host Microbe. 2019;25(1):39-48 e35. doi:10.1016/j.chom.2018.12.004

34. Bornholdt ZA, Herbert AS, Mire CE, et al. A two-antibody pan-ebolavirus cocktail confers broad therapeutic protection in ferrets and nonhuman primates. Cell Host Microbe. 2019;25(1):49-58 e45. doi:10.1016/j.chom.2018.12.005

35. Wec AZ, Nyakatura EK, Herbert AS, et al. A "Trojan horse" bispecific-antibody strategy for broad protection against ebolaviruses. Science. 2016;354(6310):350-354. doi:10.1126/science.aag3267

36. Davey RT Jr; PREVAIL II Writing Group, Multi-National PTEVAIL II Study Team. A randomized, controlled trial of ZMapp for Ebola Virus Infection. $N$ Engl J Med. 2016;375(15):1448-1456.
37. Gaudinski MR, Coates EE, Novik L, et al. Safety, tolerability, pharmacokinetics, and immunogenicity of the therapeutic monoclonal antibody mAb114 targeting Ebola virus glycoprotein (VRC 608): an open-label phase 1 study. Lancet. 2019;393(10174):889-898. doi:10.1016/S0140-6736(19)30036-4

38. Sivapalasingam S, Kamal M, Slim R, et al. Safety, pharmacokinetics, and immunogenicity of a co-formulated cocktail of three human monoclonal antibodies targeting Ebola virus glycoprotein in healthy adults: a randomised, first-in-human phase 1 study. Lancet Infect Dis. 2018;18(8):884-893. doi:10.1016/S1473-3099(18)30397-9

39. Ottoni MP, Ricciardone JD, Nadimpalli A, et al. Ebola-negative neonates born to Ebola-infected mothers after monoclonal antibody therapy: a case series. Lancet Child Adolescent Health. 2020;4 (12):884-888. doi:10.1016/S2352-4642(20)30278-9

40. Mulangu S, Dodd LE, Davey RT Jr, et al. A randomized, controlled trial of Ebola Virus disease therapeutics. $N$ Engl J Med. 2019;381 (24):2293-2303. doi:10.1056/NEJMoa1910993

41. Regeneron. Regeneron's antibody cocktail REGN-EB3 is first FDAapproved treatment for Ebola; 2020. Available from: https://investor.regen eron.com/news-releases/news-release-details/regenerons-antibodycocktail-regn-eb3-inmazebr-first-fda. Accessed March 5, 2021.

42. Wang BX, Fish EN. The yin and yang of viruses and interferons. Trends Immunol. 2012;33(4):190-197. doi:10.1016/j.it.2012.01.004

43. Messaoudi I, Amarasinghe GK, Basler CF. Filovirus pathogenesis and immune evasion: insights from Ebola virus and Marburg virus. Nat Rev Microbiol. 2015;13(11):663-676. doi:10.1038/nrmicro3524

44. Jahrling PB, Geisbert TW, Geisbert JB, et al. Evaluation of immune globulin and recombinant interferon- $\alpha 2 b$ for treatment of experimental ebola virus infections. J Infect Dis. 1999;179(179):S224-S234. doi: $10.1086 / 514310$

45. Smith LM, Hensley LE, Geisbert TW, et al. Interferon-beta therapy prolongs survival in rhesus macaque models of Ebola and Marburg hemorrhagic fever. J Infect Dis. 2013;208(2):310-318. doi:10.1093/ infdis/jis921

46. McCarthy SD, Majchrzak-Kita B, Racine T, et al. A rapid screening assay identifies monotherapy with interferon-ss and combination therapies with nucleoside analogs as effective inhibitors of Ebola Virus. PLoS Negl Trop Dis. 2016;10(1):e0004364. doi:10.1371/journal.pntd.0004364

47. Konde MK, Baker DP, Traore FA, et al. Interferon beta-1a for the treatment of Ebola virus disease: a historically controlled, single-arm proof-of-concept trial. PLoS One. 2017;12(2):e0169255. doi:10.1371/ journal.pone. 0169255

48. Kondratowicz AS, Lennemann NJ, Sinn PL, et al. T-cell immunoglobulin and mucin domain 1 (TIM-1) is a receptor for Zaire Ebolavirus and Lake Victoria Marburgvirus. Proc Natl Acad Sci U S A. 2011;108 (20):8426-8431. doi:10.1073/pnas.1019030108

49. Ji X, Olinger GG, Aris S, Chen Y, Gewurz H, Spear GT. Mannosebinding lectin binds to Ebola and Marburg envelope glycoproteins, resulting in blocking of virus interaction with DC-SIGN and complement-mediated virus neutralization. J Gen Virol. 2005;86(Pt 9):2535-2542. doi:10.1099/vir.0.81199-0

50. Michelow IC, Lear C, Scully C, et al. High-dose mannose-binding lectin therapy for Ebola virus infection. J Infect Dis. 2011;203 (2):175-179. doi:10.1093/infdis/jiq025

51. Johnson JC, Martinez O, Honko AN, Hensley LE, Olinger GG, Basler CF. Pyridinyl imidazole inhibitors of p38 MAP kinase impair viral entry and reduce cytokine induction by Zaire ebolavirus in human dendritic cells. Antiviral Res. 2014;107:102-109. doi:10.10 16/j.antiviral.2014.04.014

52. Hensley LE, Stevens EL, Yan SB, et al. Recombinant human activated protein $\mathrm{C}$ for the postexposure treatment of Ebola hemorrhagic fever. J Infect Dis. 2007;196(Suppl 2):S390-S399. doi:10.1086/520598

53. Geisbert TW, Hensley LE, Jahrling PB, et al. Treatment of Ebola virus infection with a recombinant inhibitor of factor VIIa/tissue factor: a study in rhesus monkeys. Lancet. 2003;362(9400):19 53-1958. doi:10.1016/S0140-6736(03)15012-X 
54. Wolf T, Kann G, Becker S, et al. Severe Ebola virus disease with vascular leakage and multiorgan failure: treatment of a patient in intensive care. Lancet. 2015;385(9976):1428-1435. doi:10.1016/S01 40-6736(14)62384-9

55. Poliquin G, Funk D, Jones S, et al. Impact of intensive care unit supportive care on the physiology of Ebola virus disease in a universally lethal non-human primate model. Intensive Care Med Exp. 2019;7(1):54. doi:10.1186/s40635-019-0268-8

56. Zeng X, Blancett CD, Koistinen KA, et al. Identification and pathological characterization of persistent asymptomatic Ebola virus infection in rhesus monkeys. Nat Microbiol. 2017;2(9):17113. doi:10.10 38/nmicrobiol.2017.113

57. Sagui E, Janvier F, Baize S, et al. Severe Ebola virus infection with encephalopathy: evidence for direct virus involvement. Clin Infect Dis. 2015;61(10):1627-1628. doi:10.1093/cid/civ606
58. Jacobs M, Rodger A, Bell DJ, et al. Late Ebola virus relapse causing meningoencephalitis: a case report. Lancet. 2016;388(10043):4 98-503. doi:10.1016/S0140-6736(16)30386-5

59. de Greslan T, Billhot M, Rousseau C, et al. Ebola virus-related encephalitis. Clin Infect Dis. 2016;63(8):1076-1078. doi:10.1093/ cid/ciw469

60. Varkey JB, Shantha JG, Crozier I, et al. Persistence of Ebola virus in ocular fluid during convalescence. $N$ Engl J Med. 2015;372(25): 2423-2427. doi:10.1056/NEJMoa1500306

61. Deen GF, Broutet N, Xu W, et al. Ebola RNA persistence in semen of ebola virus disease survivors - final report. $N$ Engl J Med. 2017;377 (15):1428-1437. doi:10.1056/NEJMoa1511410

62. Mate SE, Kugelman JR, Nyenswah TG, et al. Molecular evidence of sexual transmission of ebola virus. $N$ Engl J Med. 2015;373 (25):2448-2454. doi:10.1056/NEJMoa1509773

\section{Publish your work in this journal}

Biologics: Targets and Therapy is an international, peer-reviewed journal focusing on the patho-physiological rationale for and clinical application of Biologic agents in the management of autoimmune diseases, cancers or other pathologies where a molecular target can be identified. This journal is indexed on PubMed Central, CAS, EMBase,
Scopus and the Elsevier Bibliographic databases. The manuscript management system is completely online and includes a very quick and fair peer-review system, which is all easy to use. Visit http://www.dovepress.com/testimonials.php to read real quotes from published authors. 